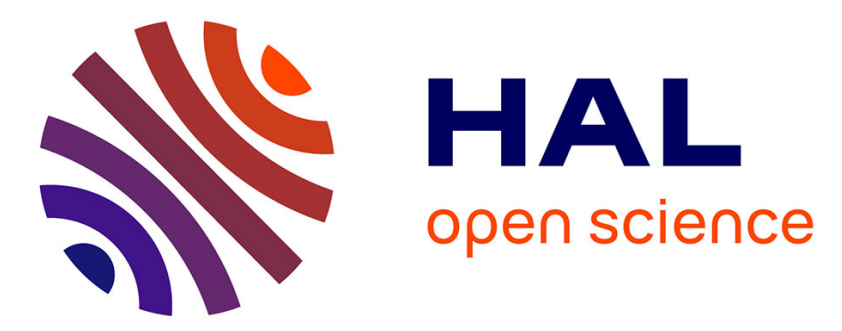

\title{
Redox-Active Vertically Aligned Mesoporous Silica Thin Films as Transparent Surfaces for Energy Storage Applications
}

\author{
Jianren Wang, Neus Vilà, Alain Walcarius
}

\section{> To cite this version:}

Jianren Wang, Neus Vilà, Alain Walcarius. Redox-Active Vertically Aligned Mesoporous Silica Thin Films as Transparent Surfaces for Energy Storage Applications. ACS Applied Materials \& Interfaces, 2020, 12 (21), pp.24262-24270. 10.1021/acsami.0c03650 . hal-02981478

\section{HAL Id: hal-02981478 \\ https://hal.univ-lorraine.fr/hal-02981478}

Submitted on 26 Nov 2020

HAL is a multi-disciplinary open access archive for the deposit and dissemination of scientific research documents, whether they are published or not. The documents may come from teaching and research institutions in France or abroad, or from public or private research centers.
L'archive ouverte pluridisciplinaire HAL, est destinée au dépôt et à la diffusion de documents scientifiques de niveau recherche, publiés ou non, émanant des établissements d'enseignement et de recherche français ou étrangers, des laboratoires publics ou privés. 


\section{Redox-active vertically-aligned mesoporous silica}

\section{thin films as transparent surfaces for energy storage}

\section{applications}

Jianren Wang, Neus Vilà, Alain Walcarius*

Laboratoire de Chimie Physique et Microbiologie pour les Matériaux et l'Environnement (LCPME), UMR 7564 CNRS-Université de Lorraine, 405 rue de Vandoeuvre, 54600 Villers-lèsNancy, France

\section{KEYWORDS}

Mesoporous silica film; transparent electrode; energy storage material; organic-inorganic hybrid; redox-active membrane; ferrocene; cobaltocenium; graphene oxide 


\section{ABSTRACT}

Organic-inorganic hybrid membranes made of a high density of redox active moieties covalently bonded to the internal surfaces of vertically-aligned mesoporous silica thin films are relevant for applications in transparent energy storage devices. This is demonstrated here on the basis of functionalized transparent mesoporous silica thin films prepared on indium-tin oxide electrode from the combination of an electrochemically-induced self-assembly method (to generate azide functionalized silica) and a copper-catalyzed azide-alkyne click reaction (to derivatize the material with electroactive groups). The very small thickness $(105 \mathrm{~nm})$ and the uniformly distributed vertical mesochannels with ultranarrow diameter $(2 \mathrm{~nm})$ make the hybrid film a promising substrate that not only achieves transparency of $82 \%$, but also provides large surface area to accommodate a high density of redox active species such as ferrocene. In such rigid and insulating porous membranes, the charge transfer reactions take place through a pure electron-hopping mechanism between adjacent redox sites, which are favored by the ordered and oriented mesostructure containing large amounts of uniformly distributed ferrocene functions in the mesochannels. Their performance results from both high charge transfer rates (electron hopping) and easy mass transport (fast diffusion of counter ions). The most effective system is the ferrocenefunctionalized silica film prepared from $40 \%$ organosilane, which is able to deliver a capacity of $105 \mathrm{C} \mathrm{cm}^{-3}\left(1.10 \mathrm{mC} \mathrm{cm}^{-2}\right)$ at the current density of $0.4 \mathrm{~A} \mathrm{~cm}^{-3}$. (with up to $48 \%$ capacity retention achieved at a charging time as short as $2.8 \mathrm{~s}$ ). Such electrode can be associated to an electrodeposited graphene cathode in a solid-state battery-capacitor hybrid device which can deliver $0.74 \mathrm{mC} \mathrm{cm}^{-2}$ at a potential scan rate of $20 \mathrm{mV} \mathrm{s}^{-1}$. The azide-functionalized mesoporous silica film is actually a versatile platform that can be functionalized with different redox molecules, as shown here for cobaltocenium moieties, which may broaden its application field. 


\section{INTRODUCTION}

Transparent electronic systems have drawn considerable attention in recent years, representing the cutting-edge technology for next-generation electronic devices, such as touch screens, optical circuits, ${ }^{1}$ displays, ${ }^{2,3}$ and solar cells, ${ }^{4,5}$ etc. The in-situ integration of energy storage components acting as power source is a crucial step to developing such devices, which puts forward a transparency requirement for energy storage devices..${ }^{6,7}$ Among various energy storage systems, supercapacitors featuring high power density, fast charge-discharge rates and long cycling life, are among the most prominent candidates for this emerging field. ${ }^{8}$ One of the most decisive factors to prepare the transparent energy storage electrode is to precisely control the thickness of active materials to keep high transparency. ${ }^{9}$ This could be basically always achievable by decreasing the thickness of the materials constituting the active layer, but meanwhile, the resulting energy storage performance would be also limited by too low amounts of active materials. Therefore, the main difficulty lies in how to improve the energy storage ability of materials to strike the right balance between the transparency and the energy/power density. Despite extensive efforts, the rational construction of electrode materials combining both excellent transparency and superior energy/power density remains a challenge.

According to the energy storage mechanisms, the "capacitive" materials can be classified into two major types: carbon-based materials for classical capacitors and faradic materials for so-called supercapacitors. As one representative of the former, graphene, a $2 \mathrm{D}$ carbon material $(\sim 0.34 \mathrm{~nm})$ with huge surface area $\left(\sim 2630 \mathrm{~m}^{2} \mathrm{~g}^{-1}\right)$ and outstanding conductivity $\left(\sim 2000 \mathrm{~S} \mathrm{~m}^{-1}\right)$, is widely used to construct transparent energy storage devices based on ultra-thin coatings. ${ }^{10}$ For example, Chou 
et al. prepared 4-layers graphene film with ultra-high transparency of $\sim 90 \%$ by utilizing a chemical vapor deposition method. ${ }^{11}$ However, the capacity of this film was only $4.27 \mu \mathrm{F} \mathrm{cm}^{-2}$ at a scan rate of $20 \mathrm{mV} \mathrm{s}^{-1}$, because charges/ions can only be stored on its surface via a pure physical electrical double-layer process. In contrast, faradic materials can always gain much higher energy density at similar thickness by involving additional chemical redox reactions. ${ }^{12}$ Recently, the Yang's group reported a transparent $\mathrm{Co}_{3} \mathrm{O}_{4}$ nanoparticles electrode with the transparency of $\sim 70 \%$ and a much higher energy density of $6.03 \mathrm{mF} \mathrm{cm}{ }^{-2}$ at a scan rate of $1 \mathrm{mV} \mathrm{s}^{-1} .{ }^{13}$ Nevertheless, the rate performance of this electrode was severely restricted by its poor charge transfer kinetics and slow solid-diffusion process of counterions during the redox reaction. The capacity retention of this electrode was only $57 \%$ at a moderate scan rate of $20 \mathrm{mV} \mathrm{s}^{-1}$, with unstable charges output at different rates which would make difficult its adaptation for practical applications. Therefore, seeking new redox systems likely to accelerate the electron transfer reactions is of great importance for the electrode material to gain high energy density while maintaining excellent rate performance.

On the basis of our understanding of these technical needs, a system based on an electron-hopping mechanism between redox adjacent sites inside an ordered, large surface area and transparent matrix may have the potential to improve the charge transfer processes. Different from the traditional electron transfer mechanism where the physical contact between the redox sites is required, the electrons can freely transfer between the close but isolated adjacent redox centers through an electron-hopping process (as that operating in redox polymers, ${ }^{14}$ for instance). As investigated for self-assembled monolayers on electrodes, the kinetics of this electron hopping mechanism has been proven efficient enough as far as the active sites are close enough. ${ }^{15}$ However, the limited amount of active sites of monolayer-based systems restrict their energy density, and 
the implementation of redox molecular junctions in large-scale and three-dimensional assemblies remains challenging, especially in view of avoiding other possible charge transfer ways (e.g., translational motion of polymer chains in redox-active supramolecular systems ${ }^{16}$ ). Therefore, to best our knowledge, except for "between-particle" charge transport phenomena in metal oxidebased electrodes,${ }^{17}$ there is no related work that systematically assesses the value of molecular electron-hopping processes in the energy storage field.

Our group has established an Electro-Assisted Self-Assembly (EASA) method to generate thin layers of vertically-aligned mesoporous silica on various conductive substrates, ${ }^{18,19}$ and further achieved their surface functionalization by click chemistry (following Copper-catalyzed AzideAlkyne Cycloaddition, CuAAC)) to introduce large amounts of organic groups onto the internal silica walls. ${ }^{20,21}$ If introducing redox active centers in such system, the resulting rigid organicinorganic hybrid becomes electroactive and electron-hopping becomes the only possible way to conduct the electrons among the redox centers due to the isolating nature of the silica walls. ${ }^{22}$ Furthermore, the density of the redox molecules in the film can be adjusted by varying the components of the precursor solution. ${ }^{20,21}$ Both features make such thin, ordered and oriented, transparent organic-inorganic hybrid film an ideal platform to evaluate the interest of the electronhopping process in offering possibilities to construct new types of energy storage materials. This is thus what we have investigated here on the basis of electrodes modified with mesoporous silica films generated by EASA and functionalized with metallocene redox centers (ferrocene, cobaltocenium), going up to their association to a graphene counter electrode to form a solid-state battery-capacitor hybrid device. 


\section{EXPERIMENTAL}

\subsection{Chemicals and reagents}

Tetraethoxysilane (TEOS, 98\%), 3-chloropropyltrimethoxysilane (Cl-PTES, 97\%) and graphite were purchased from Alfa Aesar and cetyltrimethylammonium bromide (CTAB, 99\%) from Acros. Acetonitrile (ACN, 99\%), dimethylformamide (DMF, 99\%) and cyclohexane (99\%) were obtained from Merck. Ethynylferrocene (97\%), lithium perchlorate (95\%), lithium chloride (95\%), copper sulfate (99\%), Sodium diethyldithiocarbamate trihydrate, and $\mathrm{HCl}(37 \%)$ were purchased from Sigma-Aldrich. Sodium nitrate (99\%), ascorbic acid (97\%), tetrabutylammonium bromide (99\%) and poly(vinyl alcohol) (PVA, MW $=72000 \mathrm{~g} / \mathrm{mol})$ originated from Fluka. All compounds were used directly without further purification.

Preparation of 3-azidopropyltrimethoxysilane (AzPTMS). The AzPTMS precursor was synthesized by adding $2 \mathrm{~g}$ of Cl-PTES, $1.08 \mathrm{~g}$ sodium azide and $1.29 \mathrm{~g}$ tetrabutylammonium bromide) in $100 \mathrm{~mL} \mathrm{ACN}$, which was stirred and refluxed at $90{ }^{\circ} \mathrm{C}$ for $24 \mathrm{~h}$ under nitrogen atmosphere. Then, the ACN solvent was removed by rotary evaporation at $80{ }^{\circ} \mathrm{C}$ under a vacuum of 0.2 bar. The residual mixture was suspended in cyclohexane and filtered with filter paper. The residual cyclohexane was further removed by rotary evaporation at $80^{\circ} \mathrm{C}$ under pressure of 0.2 bar and the oily Az-PTMS can be finally obtained. Yield: $\sim 1.3 \mathrm{~g}, 65 \% .{ }^{1} \mathrm{H} \mathrm{NMR}\left(400 \mathrm{MHz}, \mathrm{CDCl}_{3}\right)$ : $\delta(\mathrm{ppm}) 3.82(\mathrm{~s}, 9 \mathrm{H}), 3.65(\mathrm{t}, 2 \mathrm{H}, 8.25 \mathrm{~Hz}), 1.24(\mathrm{~m}, 2 \mathrm{H}), 0.75(\mathrm{t}, 2 \mathrm{H}, 8.31 \mathrm{~Hz})$.

\subsection{Thin films synthesis, electrodes and devices fabrication}

The indium-tin oxide (ITO) plates (surface resistivity of $8 \sim 12 \Omega$ ) was obtained from Delta Technologies. 
Preparation of azide-functionalized mesoporous silica films (Az-MS). The azide-functionalized vertically-aligned mesoporous silica thin films were prepared through the EASA method. ${ }^{20}$ Firstly, the silane sol was prepared by adding $120 \mathrm{mM}$ TEOS and Az-PTMS (at Az-PTMS/TEOS molar ratios equal to ranging $20 \%, 40 \%$ or $60 \%$ ) in a solution containing $20 \mathrm{~mL}$ ethanoland $20 \mathrm{~mL}$ water with $0.1 \mathrm{M} \mathrm{NaNO}_{3}$. Then, $1.35 \mathrm{mmol} \mathrm{CTAB}$ was added under stirring and the $\mathrm{pH}$ was adjusted to 3 by using $0.1 \mathrm{M} \mathrm{HCl}$ aqueous solution. The resulting sol was stirred at room temperature for 2.5 $\mathrm{h}$ for ageing. The mesoporous functionalized silica films were grown on ITO electrode in the potentiostatic mode by applying a cathodic potential of $-1.3 \mathrm{~V}$ vs. Ag wire pseudo-reference for $20 \mathrm{~s}$. The electrode surface was immediately rinsed with water and dried overnight at $130^{\circ} \mathrm{C}$. The CTAB surfactant was extracted from the film by dipping it into an ethanolic solution containing $0.1 \mathrm{M} \mathrm{HCl}$ with moderate magnetic stirring for $10 \mathrm{~min}$ and the obtained sample was labeled as AzMS.

Preparation of the ferrocene functionalized mesoporous silica (Fc-MS) thin films. The above AzMS films were further derivatized with ferrocene molecules by covalent bonding through click chemistry. ${ }^{20}$ Az-MS was first dipped into a mixed $\mathrm{DMF} / \mathrm{H}_{2} \mathrm{O}(12 / 8 \mathrm{~mL})$ solvent containing ethynylferrocene $\left(10.0 \mathrm{mg}, 4.6 \times 10^{-2} \mathrm{mmol}\right)$, copper sulfate $\left(3.5 \mathrm{mg}, 1.4 \times 10^{-2} \mathrm{mmol}\right)$, and ascorbic acid $\left(7.5 \mathrm{mg}, 4.3 \times 10^{-2} \mathrm{mmol}\right)$ and the resulting mixture was protected from light and allowed to react for $24 \mathrm{~h}$ in order to perform the click reaction between the ethynylferrocene and the azido groups on the silica surface. After reaction, the film was collected and soaked in $1 \mathrm{mM}$ sodium diethyldithiocarbamate in ethanol solution to remove the remaining copper catalyst. Followed by rinsing with water and drying at room temperature, the ferrocene functionalized mesoporous silica film can be finally obtained. The samples derived from 20\%, 40\%, 60\% Az-PTMS in precursor sol were labelled as Fc-MS-20, Fc-MS-40, Fc-MS-60, respectively. Fc-MS-40 was primarily 
exploited in this work, the other samples Fc-MS-20 and Fc-MS-60 being only used for comparison purposes.

Preparation of a cobaltocenium functionalized mesoporous silica $\left(\mathrm{Co}^{+}-\mathrm{MS}\right)$ thin film. $\mathrm{A} \mathrm{Co}^{+}-\mathrm{MS}-$ 40 film was prepared similarly as the Fc-MS-40 sample, but by replacing ethynylferrocene by the ethynylcobaltocenium molecule, ${ }^{23}$ to get the surface of the silica channels covered with covalentlybonded cobaltocenium moieties.

Preparation of the graphene counter-electrode. The graphene oxide (GO) was prepared from graphite powder following the classical Hummers' method. ${ }^{24}$ The graphene electrode was prepared by electrophoretic deposition of GO onto ITO, by applying $-1.2 \mathrm{~V}$ (vs. $\mathrm{Ag} / \mathrm{AgCl}$ ) to the ITO electrode for $30 \mathrm{~s}$ in $30 \mathrm{~mL}$ solution containing $50 \mathrm{mg} \mathrm{GO}$ and $0.32 \mathrm{~g} \mathrm{LiClO}_{4}$ as supporting electrolyte.

Preparation of the asymmetric solid-state device. A PVA/LiCl gel was prepared by dissolving 6.37 g LiCl and 3 g PVA in $37 \mathrm{~mL}$ water at $90{ }^{\circ} \mathrm{C} .{ }^{25}$ The device was assembled with a sandwich configuration by using the Fc-MS-40 $\left(1 \mathrm{~cm}^{-2}\right)$ as the cathode, the graphene electrode $\left(1 \mathrm{~cm}^{-2}\right)$ as the anode and a PET plate (thickness $\sim 1 \mathrm{~mm}$ ) with a hole in the center as separator. Several droplets of the PVA/LiCl gel were added between the two electrodes and several clamps were used to fix the device.

\subsection{Apparatus}

Electrochemical measurements. Cyclic voltammetry experiments and recording charge and discharge curves were performed using $\mu$ Autolab potentiostat with a three-electrode system. The 
as-prepared redox active films, an $\mathrm{Ag} / \mathrm{AgCl}(3.5 \mathrm{M} \mathrm{KCl})$ electrode and a stainless steel, were used as the working electrode, reference and counter electrodes, respectively.

Other characterization techniques. Transmission electron microscopy (TEM) investigation was performed with a JEOL ARM 200F - Cold FEG TEM/STEM equipped with a GIF Quantum ER. Fourier transform infrared spectroscopy (FTIR) measurement was carried out using a Nicolet 8700 apparatus equipped with a diffuse reflectance accessory (Smart Collector). Grazing-Incidence Small-Angle X-ray Scattering (GISAXS) pattern was obtained using the Nanoviewer from Rigaku ( $\mathrm{CuK} \alpha$ radiation). The angle of incidence of the X-ray beam with respect to the film surface was set at $0.22^{\circ}$. The profilometry measurements were performed using the Dektak XT apparatus.

\section{RESULTS AND DISCUSSIONS}

3.1. Main characteristics of the ferrocene-functionalized mesoporous silica films

The overall preparation of ferrocene-functionalized vertically-aligned mesoporous silica thin films is schematically illustrated in Figure 1, involving the EASA generation of an azide-functionalized silica membrane onto the ITO surface, which is further derivatized with ferrocene units by coppercatalyzed azide-alkyne Huisgen reaction. 


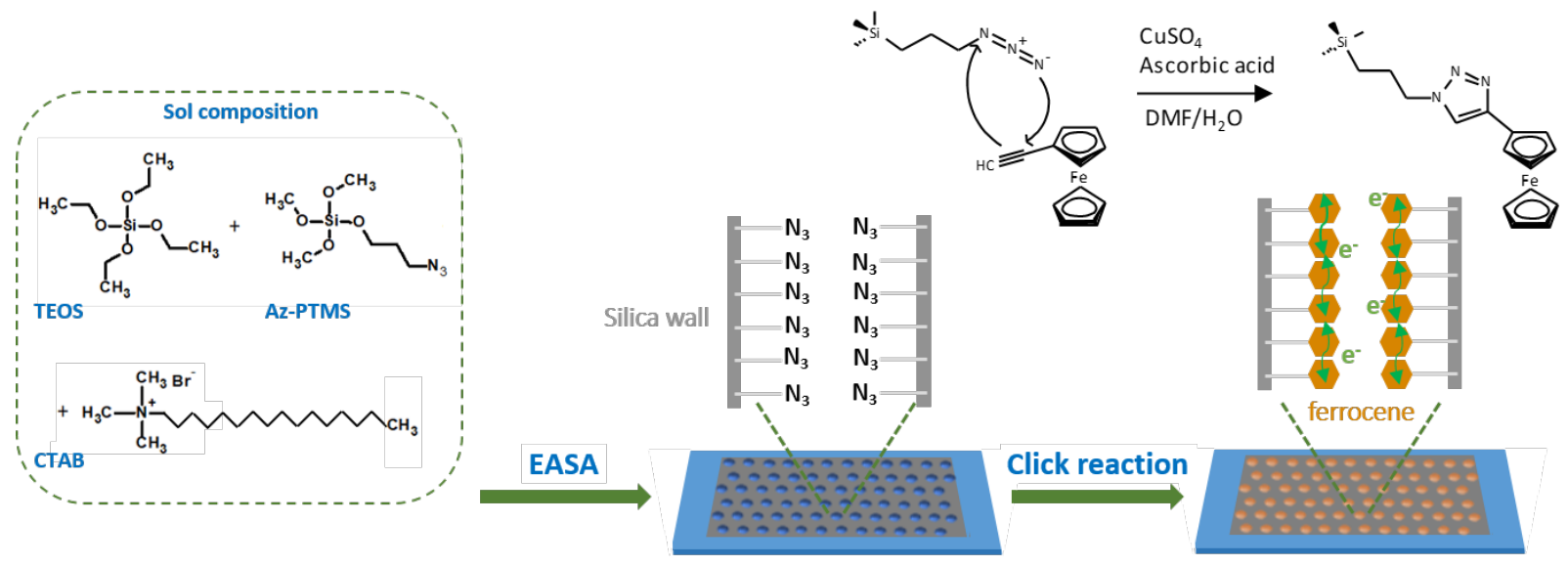

Figure 1. Schematic illustration of the preparation process of the ferrocene-functionalized vertically-aligned mesoporous silica thin films on a flat ITO electrode. After hydrolysis of the silane precursors the azide-functionalized silica thin films are further functionalized with ferrocene units by copper-catalyzed azide-alkyne Huisgen reaction.

The main structural characteristics of the ferrocene-functionalized silica thin film prepared with 40\% AzPTMS $+60 \%$ TEOS precursors (Fc-MS-40) are shown in Figure 2. Top view TEM micrographs (see parts (a)and (b) in Fig. 2) indicate a highly porous film composed of fairly ordered hexagonal mesopores, as also identified by the hexagonal diffraction spots of the corresponding Fast Fourier Transformation (FFT) diffractogram. The cross-section view of the sample (Fig. 2c) further reveals the vertical channels run directly from the top to the bottom of the film, and the thickness of the film is $\sim 105 \mathrm{~nm}$, a value which was also confirmed by profilometry. Grazing Incidence Small Angle X-ray Scattering (GISAXS) is further used to analyze the internal structure of the film in order to obtain the statistically averaged lattice information. Two sharp diffraction spots can be observed in the equatorial plane of the scattering in (Fig. 2e), indicating the long-range ordered perpendicular structure of the film, along with a very shallow ring in-plane 
arising from few silica beads with wormlike mesostructured on the film surface (as commonly observed for films prepared by EASA ${ }^{26,27}$ Moreover, the $\mathrm{q}_{\mathrm{y}}$ value of $1.81 \mathrm{~nm}^{-1}$ can be obtained by measuring the distance between the light source and the diffraction spots (Fig. 2f). This value can be used to calculate the lattice spacing, $d$, of the structure using the equation $d=2 \pi / q,{ }^{28}$ giving rise to a $d$ value equal to $3.47 \mathrm{~nm}$, which is consistent with TEM results. Similar mesostructure characteristics can be observed for the less functionalized Fc-MS-20 film, in agreement with previous observations, ${ }^{20}$ whereas the film generated from a sol containing $60 \%$ of the organosilane AzPTMS (Fc-MS-60) was no more ordered (because of interference in the self-assembly of the mesophase structure ${ }^{29}$ ), as illustrated in Supporting Information (Fig. S1). Besides, benefiting from the its small thickness and vertical channels, the film is highly transparent, and the UV-Vis spectrum demonstrates a transmittance of $82 \%$ that can be achieved at the wavenumber of $550 \mathrm{~nm}$ (Fig. 2d), which makes possible its use in the transparency-required devices. 

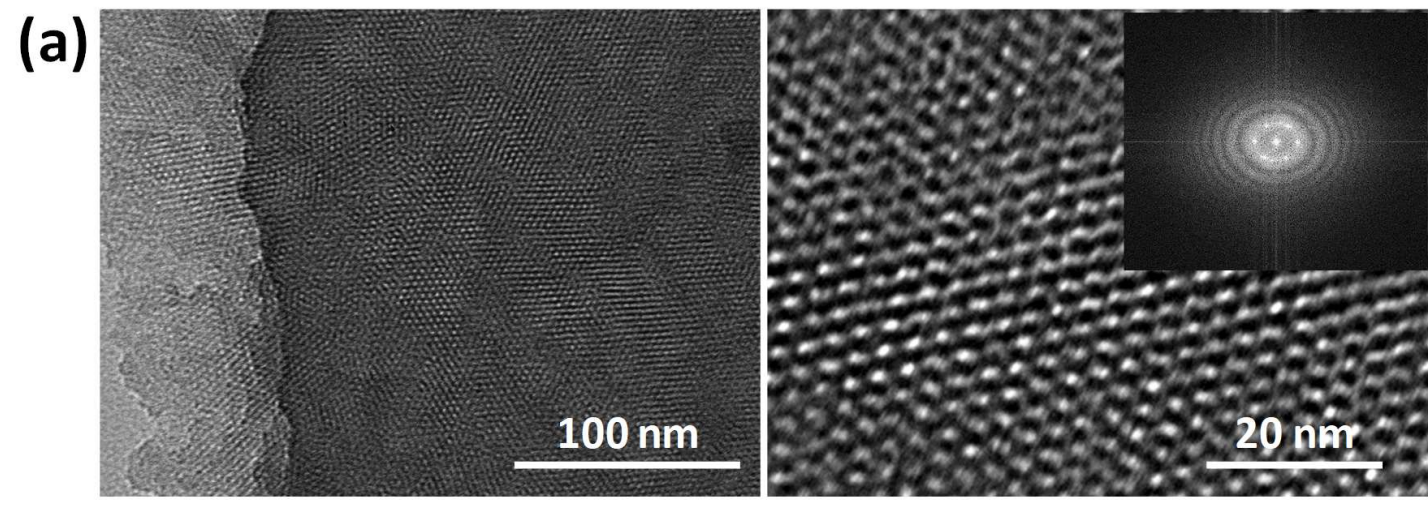

(b)
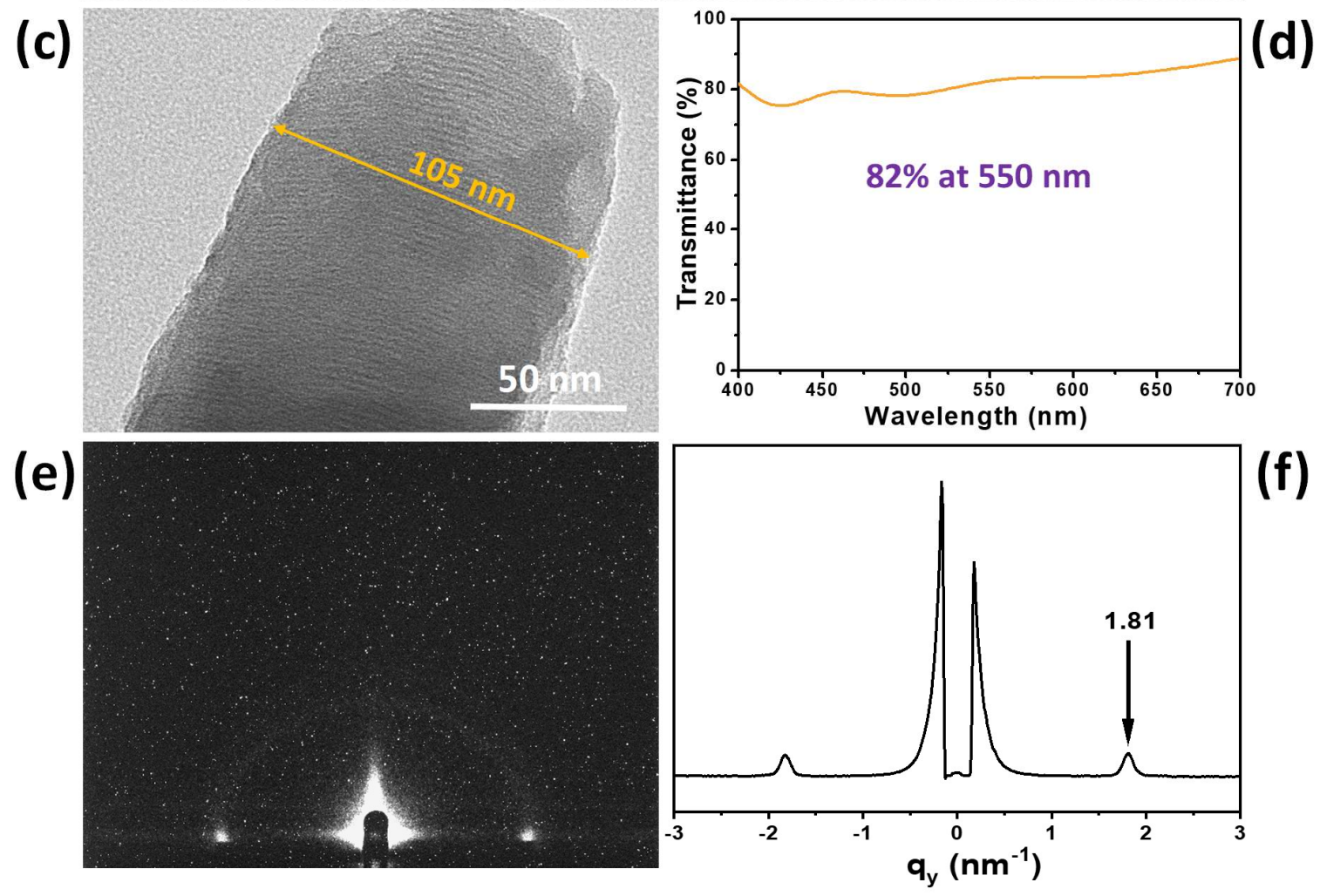

Figure 2. Structural characterization of the Fc-MS-40 film. (a-c) TEM micrographs: top views (ab), cross-section view (c), and corresponding FFT pattern (inset in (b)). (d) Transmittance spectrum. (e) GISAXS pattern and (f) corresponding fitting curve. 
The incorporation of the organic groups and effectiveness of click coupling with ferrocene moieties can be checked by infrared spectroscopy (IR). Comparing the evolution of the azide signature (stretching asymmetric band located at $2095 \mathrm{~cm}^{-1}$ ) in the IR spectra for samples prepared from sols containing 20 to $60 \%$ AzPTMS (Fig. S2a) clearly indicates the presence of increasing amounts of azide groups. After the click reaction (Fig. S2b), the area of this absorption band decreased by $85 \%$ (for Fc-MS-20), by 79\% (for Fc-MS-40) and by 75\% (for Fc-MS-60), confirming that a large part of the azido groups took part in the click reaction (100\% yield cannot be reached for steric hindrance reasons). The formation of triazole units incorporating ferrocene functions can be also noticed on the figure, via their characteristic band located at $1610 \mathrm{~cm}^{-1},{ }^{30}$ yet located in a noisy region of the spectra.

\subsection{Electrochemical characterization of the ferrocene-functionalized films}

The energy storage performance of the as-prepared Fc-MS samples was first evaluated by cyclic voltammetry $(\mathrm{CV})$ in $1 \mathrm{M} \mathrm{LiCl}$ aqueous solution (see parts a \& b in Figure 3). Comparing the $\mathrm{CV}$ curves recorded at a scan rate of $5 \mathrm{mV} \mathrm{s}^{-1}$ for samples bearing various ferrocene contents (Fig. 3a) reveals the absence of any noticeable signal for the azide-functionalized film (i.e., without ferrocene grafted onto the silica walls) while well-defined redox peaks, yet significantly distinct in shape, can be observed in the potential window from 0.0 to $+0.6 \mathrm{~V} v s$. $\mathrm{Ag} / \mathrm{AgCl}$ for the Fc-MS films. Clearly the best performance is achieved for Fc-MS-40 (i.e., prepared from 40\% AzPTMS and $60 \%$ TEOS as silane precursors), from both view points of smaller anodic-to-cathodic peaks separation and larger peak currents. This can be explained taking into accounts the electron transfer mechanism involving the electron hopping between adjacent ferrocene sites attached to the 
insulating silica film and associated counter-anions transport through the mesopore channels to maintain electroneutrality (Eq. 1): ${ }^{22}$

$\mathrm{Fc}-1 \mathrm{e}^{-}+\mathrm{X}_{(\text {sol })} \Leftrightarrow \mathrm{Fc}^{+}, \mathrm{X}_{(\text {film })}$

(with $\mathrm{Fc}=$ ferrocene; $\mathrm{Fc}^{+}=$ferricinium; $\mathrm{X}^{-}=$counter-anion; sol = solution)

In doing so, the Fc-MS-40 sample is characterized by the most attractive energy storage behavior, exhibiting an almost ideal surface-controlled redox reaction (with a pair of intense bell-shaped peaks located at $+0.35 \mathrm{~V}$ vs. $\mathrm{Ag} / \mathrm{AgCl}$, with a peak-to-peak separation of $12 \mathrm{mV}$ ). This is due to the large density of redox-active sites in the material enabling efficient electron hopping between close together ferrocene molecules uniformly distributed on the mesopore walls and easy transport of charge-compensating ions thanks to the regular and oriented mesostructure. By contrast, the FcMS-20 sample containing a lower amount of ferrocene (nearly twice as less as Fc-MS-40) not only resulted in (expected) lower peak currents (by almost two times) but also resulted in less reversible diffusion-limited signals (peak-to-peak separation equal to $70 \mathrm{mV}$ ) arising from redox sites located at a longer distance between each other (slower pseudo-diffusion of the electrons in the hopping mechanism). ${ }^{31}$ On the other hand, the sample with more ferrocene loading amount (i.e., Fc-MS-60 prepared from $60 \%$ AzPTMS and $40 \%$ TEOS as silane precursors) also exhibited a smaller current response and the redox peaks shifted to higher potential values (i.e., $+0.38 \mathrm{~V}$, with a peak-to-peak separation of $28 \mathrm{mV}$ ). This can be explained by the loss of mesostructural order (Fig. S1) and steric hindrance limiting the number of electrochemically accessible ferrocene molecules in the film and slowing down the charge compensation process (Eq. 1). Similarly, a nonordered film prepared by drop coating did not give any noticeable signal for ferrocene, confirming again the interest of EASA to provide highly electroactive mesoporous films. The Fc-MS-40 film was thus chosen as 
the most appropriate for energy storage application, and used exclusively afterwards. Note however that increasing the potential scan rate contributed to induce charge transfer limitations in the Fc-MS-40 film (Fig. 3b), the fast thin-layer behavior being maintained up to $20 \mathrm{mV} \mathrm{s}^{-1}$ and then becoming more and more rate-limited at faster scan rates (Fig. S3).

In order to evaluate the energy storage performance, the galvanostatic charge-discharge curves of Fc-MS-40 were recorded at various current densities from 0.4 to $20 \mathrm{~A} \mathrm{~cm}^{-3}$ (Fig. 3c). Different from the typical triangular curve of double-layer capacitance, the charge/discharge curves are distorted but with no clear platform (the sign of a battery behavior). This phenomenon can be explained by the fast surface redox reaction without limitation of the diffusion process. ${ }^{32}$ Besides, the similar charge and discharge time also proves that there is no side reaction, and almost all stored charges can be released during the discharge process. The related coulombic efficiency of Fc-MS-40 is given in Supporting Information (Fig. S4). The capacities are calculated based on the galvanostatic charge-discharge curves and expressed as a function of current density (Fig. 3d). The Fc-MS-40 film can deliver a capacity of $105 \mathrm{C} \mathrm{cm}^{-3}\left(1.10 \mathrm{mC} \mathrm{cm}^{-2}\right)$ at the current density of 0.4 $\mathrm{A} \mathrm{cm}^{-3}$ and the capacity retention can achieve $48 \%\left(50.4 \mathrm{C} \mathrm{cm}^{-3}\right)$ at the current density of $20 \mathrm{~A}$ $\mathrm{cm}^{-3}$ (2.8 s charging time). By contrast, the capacities of Fc-MS-20 and Fc-MS-60 were lower than that of Fc-MS-40 at the same current density (Fig. S5), consistent with the CV results and confirming the most attractive features of Fc-MS-40. The Fc-MS-40 film electrode also exhibits a robust cycling performance with $75 \%$ capacity retention after 1000 successive $\mathrm{CV}$ cycles at a scan rate of $200 \mathrm{mV} / \mathrm{s}$ (Fig. 3e) owing to the durability of covalently bonded ferrocene molecules. Moreover, the comprehensive plots between areal capacity vs. transmittance at $550 \mathrm{~nm}$ for Fc-MS40 and materials reported in recent years (Fig. 3f) reveal that Fc-MS-40 can achieve a good balance in terms of high capacitance and excellent transparency. This material also exhibits a good 
volumetric energy density, when compared with similar thin-film systems reported in literatures (Fig. S6) ${ }^{33-38}$ due to the high density of redox molecules in Fc-MS-40 $\left(\sim 1 \mathrm{mmol} \mathrm{cm}^{-3}\right)$.

(a)

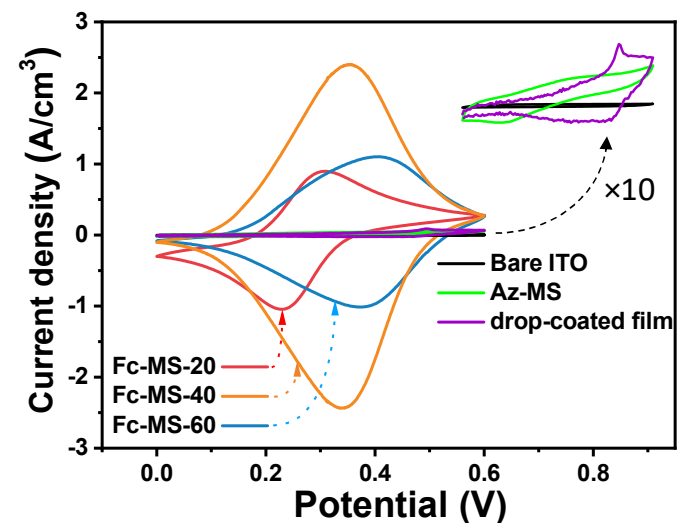

(c)

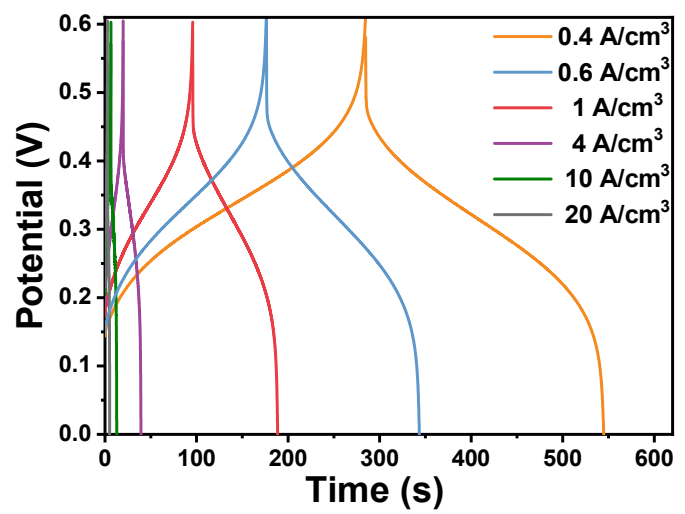

(e)

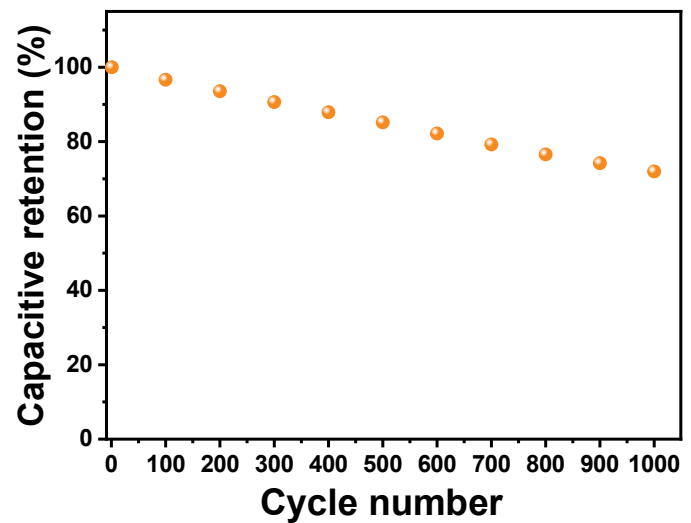

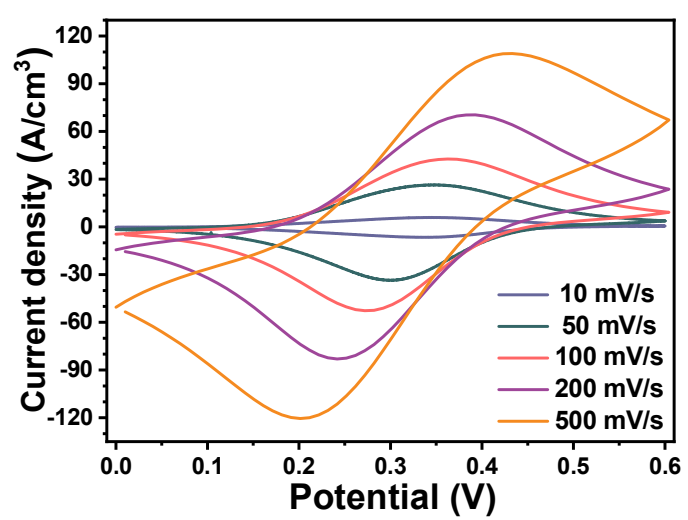

(b)
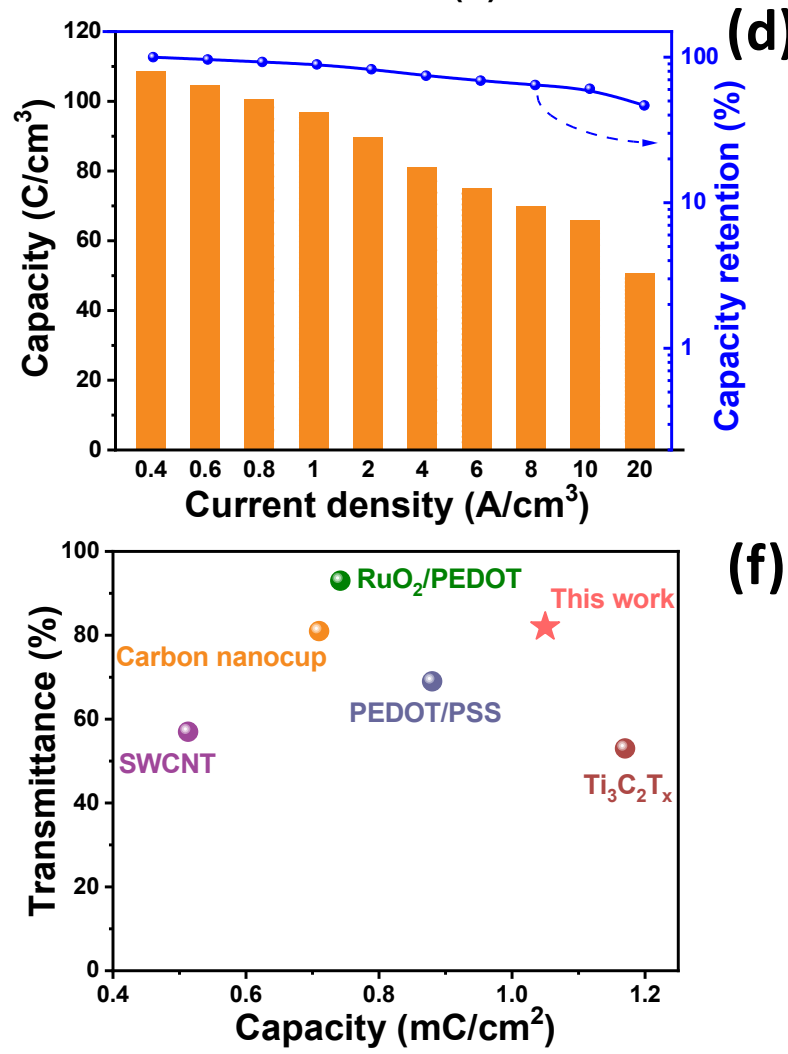

(f)

Figure 3. Energy storage performance of the ferrocene-functionalized film electrodes. (a) Comparison of the $\mathrm{CV}$ curves recorded at of $5 \mathrm{mV} \mathrm{s}^{-1}$ in $1 \mathrm{M} \mathrm{LiCl}$ using bare ITO and ITO electrodes coated with Fc-MS-20, Fc-MS-40, Fc-MS-60, Az-MS and a ferrocene-functionalized 
film prepared from drop-coating method. (b) CV curves of the Fc-MS-40 film at scan rates varying from 10 to $500 \mathrm{mV} \mathrm{s}^{-1}$. (c) Charge and discharge plots of Fc-MS-40 at various current densities from $0.4 \mathrm{~A}$ to $20 \mathrm{~A} \mathrm{~cm}^{-3}$. (d) Specific capacity $v s$. current density plots of Fc-MS-40. (e) Cycling performance at scan rate of $200 \mathrm{mV} \mathrm{s}^{-1}$ (capacity retention). (f) Transmittance $v s$. areal capacity for Fc-MS-40 (this work) and other materials reported in recent years: PEDOT/PSS, ${ }^{37}$ $\mathrm{RuO}_{2} / \mathrm{PEDOT}^{38}{ }^{3} \mathrm{SWCNT},{ }^{39}$ carbon nanocup ${ }^{40}$ and $\mathrm{Ti}_{3} \mathrm{C}_{2} \mathrm{~T}_{\mathrm{x}} \cdot{ }^{41}$

Electron-hopping is indeed the only way to transfer electrons in our system because of the insulating character of the silica walls (the resistivity of silica is very huge, ranging from $10^{12} \sim 10^{14}$ $\Omega / \mathrm{cm}^{42}$ ). This is also confirmed by a control experiment showing the absence of signal for redox species in solution when the electrode surface is covered with a surfactant-templated mesoporous silica film (Fig. S7). In the goal to characterize the electron-hopping processes in a more quantitative way, one can go deeper in the analysis of the CV curves of ferrocene-functionalized silica films recorded at different scan rates (Fig. 3b, Fig. S8). Illustrative results are shown on Figure 4. First of all, the redox peak currents $(i) v s$. scan rates $(v)$ are fitted with the equation of $i=a v^{b}$, where the empirical $b$ value is an indicator of the energy storage behavior. If $b$ value is equal to 0.5 , it means that the energy storage process proceeds according to a diffusion-controlled behavior (battery-type electrode). If $b$ value equal to 1 , then it is an ideal surface-controlled behavior (supercapacitor system). By fitting the CV data obtained for Fc-MS-40, the results reveal that $b$ values are very close to 1 for both the cathodic (0.97) and the anodic voltammetric peaks (0.90) over a wide sweep rate range varying from $5 \mathrm{mV} \mathrm{s}^{-1}$ to $50 \mathrm{mV} \mathrm{s}^{-1}$ and then tended to decrease (Fig. 4a). This suggests that the energy storage of Fc-MS-40 is an almost exclusive surfacecontrolled process and that diffusion starts to become a bottleneck only at larger scan rates. By contrast, $b$ values calculated for Fc-MS-20 (Fig. S8a\&b) are only around 0.4 (probably due to slow 
electron diffusion in the hopping process between more distant ferrocene moieties), whereas the ferrocene-functionalized film with higher density of redox centers but lacking mesostructural order (i.e., Fc-MS-60), gave rise to $b$ values around 0.8 (Fig. S8c\&d) indicating an overall charge transfer mechanism mainly governed by surface-controlled redox processes but also limited by the slow diffusion of counter ions. As the result, Fc-MS-40 shows the best rate performance among the three Fc-MS samples even if suffering from some diffusional limitations at higher potential scan rates but much less than Fc-MS-20 and Fc-MS-60 samples (Fig. S9). Besides, to quantitatively evaluate the contribution of surface-controlled current at a fixed scan rate, the electrochemical data extracted from CV measurements for Fc-MS-40 can be further fitted with the following equation: $i(V)=k_{1} v+k_{2} v^{0.5}$; where $\underline{i(V)}$ is the current at a given potential and $\mathrm{k}_{1} v$ and $\mathrm{k}_{2} v^{0.5}$ represent the surface-controlled current and diffusion-controlled current, respectively. ${ }^{43}$ The results (Fig. 4b) demonstrate that the greatest part of the total faradic current comes from a surface-controlled contribution ( $91.2 \%$ at the scan rate of $\left.20 \mathrm{mV} \mathrm{s}^{-1}\right)$, pointing out further that the existence of a high density of the redox species contributes to facilitate the electron hopping process (as reported for other densely packed redox-active systems ${ }^{14,15}$ ) and the suitable pore structure to reduce the ions diffusion resistance (Fig. 4c). This scheme also illustrates that no electron transfer can occur through the isolating silica walls, but only via electron hopping between adjacent ferrocene moieties (thanks to the flexibility of the alkyl arm linking them to the silica) and concomitant charge neutralization by the electrolyte ions, of course after a first electron transfer between the electrode surface and the ferrocene group located close to this surface. Finally, one can estimate the charge transfer resistance for the electron-hopping process by impedance spectroscopy (see the impedance spectrum of the Fc-MS-40 electrode in Fig. S10), from which a value of $\sim 60 \Omega$ can be 
observed, confirming the possible long-range charge transport in a film, however, made of an insulating material.
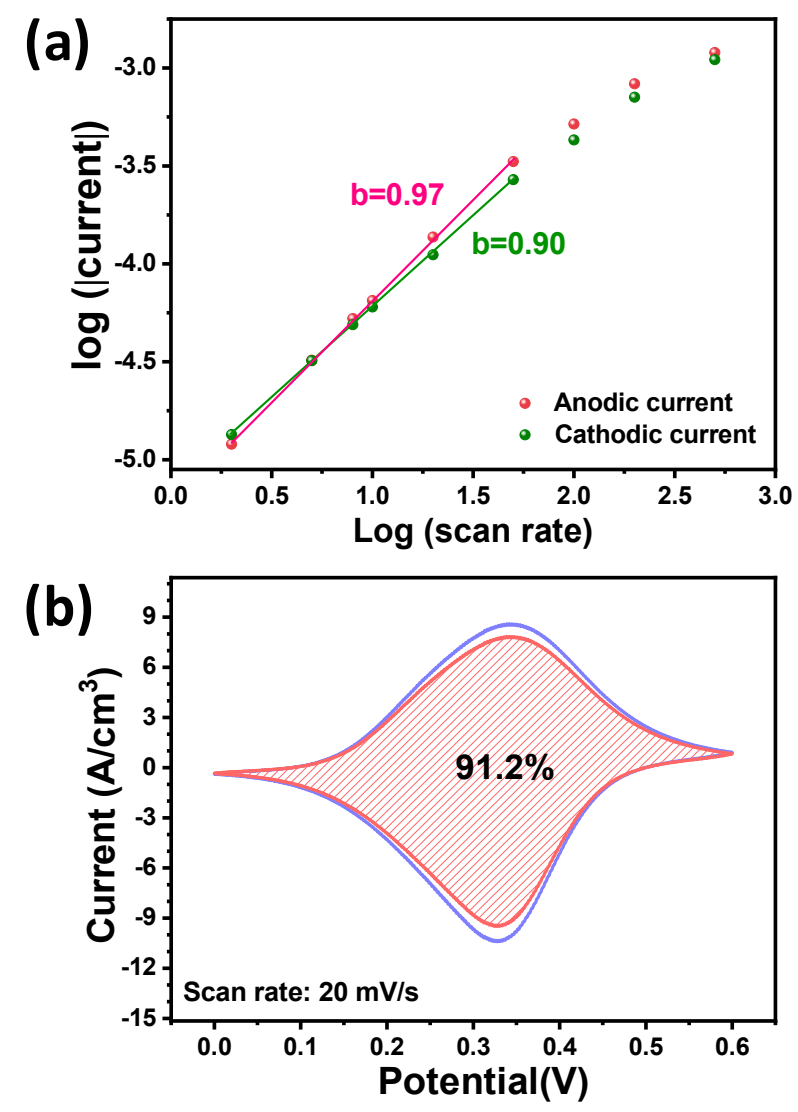

(c)

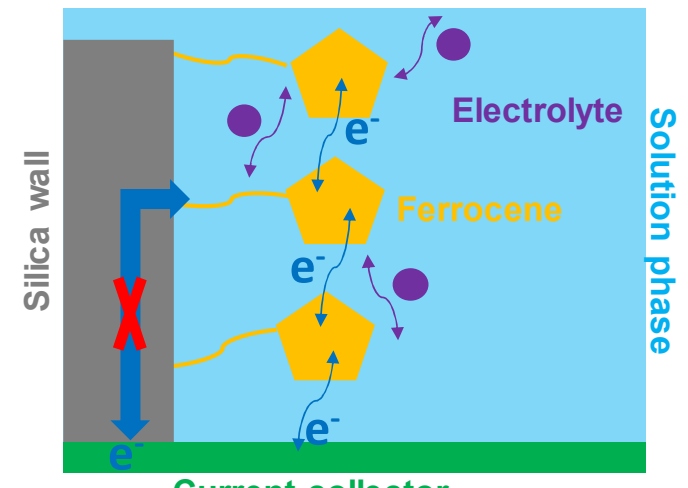

Current collector

Figure 4. Analysis of the redox process of Fc-MS-40. (a) Variation of the anodic and cathodic peak currents recorded by $\mathrm{CV}$ as a function of the potential scan rates (log scale). (b) Capacitive 
contribution of the oxidation process at the scan rate of $20 \mathrm{mV} \mathrm{s}^{-1}$ marked by the shaded region. (c) Illustration of the electron-hopping redox process taking place in the ferrocene-functionalized mesoporous silica film (electron hopping between adjacent ferrocene sites and charge neutralization by the electrolyte anions, according to equation 1, whereas no possible electron transport through the insulating silica walls).

\subsection{Extension to cobaltocenium-functionalized mesoporous silica thin films}

Not only limited to ferrocene, further derivatization of the azide-functionalized mesoporous silica films can be extended to other species with the only requirement to contain an alkyne function in their structure. In this sense, a cobaltocenium-functionalized vertically-aligned silica thin film $\left(\mathrm{Co}^{+}-\mathrm{MS}-40\right)$ has been prepared by following an analogous procedure to the one previously described in the case of the Fc-MS films. As shown in Figure 5 (part a), the CV curves of the $\mathrm{Co}^{+}-$ MS-40 exhibits a pair of well-defined redox peaks at potentials around $-1 \mathrm{~V}$, proving that redox reactions of the immobilized cobaltocenium/cobaltocene system can also occur through the electron-hopping process in the mesoporous film. Similar to those of Fc-MS-40, the redox curves are symmetrical even at the scan rate of $500 \mathrm{mV} \mathrm{s}^{-1}$, illustrating the fast charge transfer and associated ion transport processes. The galvanostatic charge-discharge curves of $\mathrm{Co}^{+}-\mathrm{MS}-40$ were also recorded at various current densities from 4 to $20 \mathrm{~A} \mathrm{~cm}^{-3}$ and the obtained results (Fig. $5 \mathrm{~b}$ ) are indicative of fast surface-controlled redox reactions as no obvious platform can be observed during the charge-discharge processes. However, compared with that of the Fc-MS-40 sample, the coulombic efficiency of $\mathrm{Co}^{+}-\mathrm{MS}-40$ is relatively low, only $\sim 36 \%$ at the current density of $4 \mathrm{~A} \mathrm{~cm}^{-}$ ${ }^{3}$. The reason could be the existence of trace amount of oxygen in solution (even after bubbling with nitrogen) which would chemically oxidize back the cobaltocene (generated during the 
electrochemical reduction process) into cobaltocenium. Based on the discharge curves, the capacity of $\mathrm{Co}^{+}$-MS-40 can reach $105 \mathrm{C} \mathrm{cm}^{-3}$ at the current density of $4 \mathrm{~A} \mathrm{~cm}^{-3}$ and still be able to retain $68 \%$ at the current density of $40 \mathrm{~A} \mathrm{~cm}^{-3}$ (Fig. 5c).

(a)

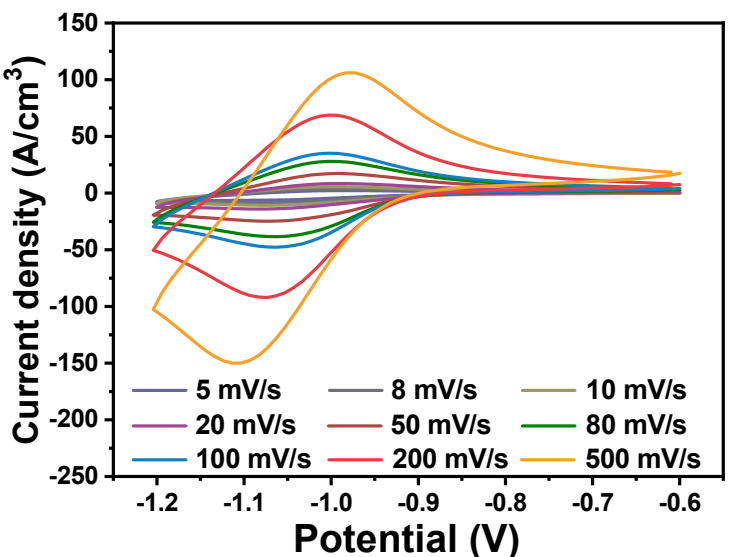

(b)

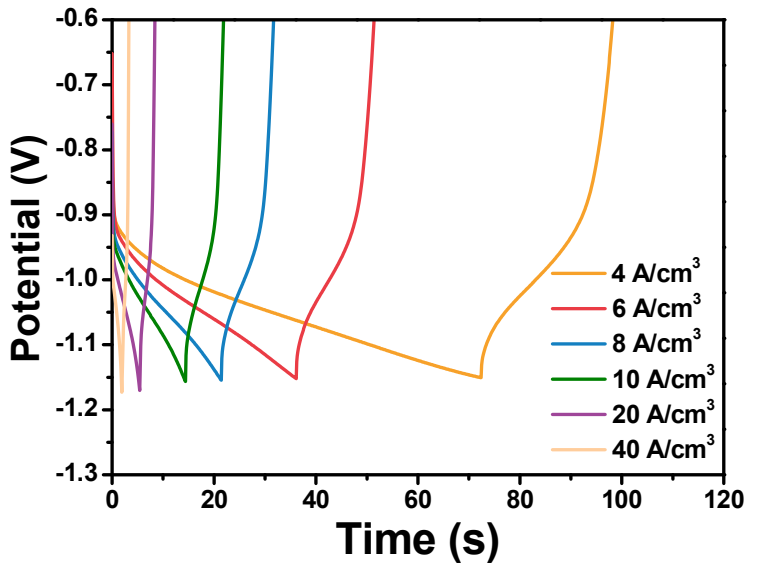

(c)

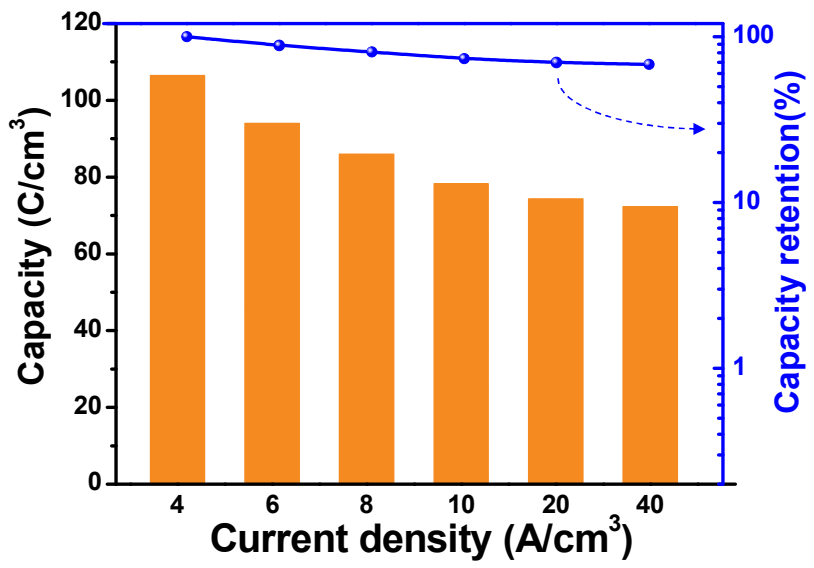


Figure 5. Energy storage performance of the cobaltocenium-functionalized film electrodes. (a) $\mathrm{CV}$ curves of the $\mathrm{Co}^{+}-\mathrm{MS}-40$ film at scan rates varying from 10 to $500 \mathrm{mV} \mathrm{s}^{-1}$. (b) Charge and discharge plots at various current densities from $0.4 \mathrm{~A}$ to $20 \mathrm{~A} \mathrm{~cm}^{-3}$. (c) Specific capacities $v s$. current density plots.

\subsection{Electrochemical response of Fc-MS-40//graphene solid-state hybrid device}

The solid-state hybrid-device is further assembled in a two-electrode set-up, by using the Fc-MS40 as the anode, polyvinyl alcohol/lithium chloride gel as separator electrolyte, and electrodeposited graphene as the cathode material. The capacity of the electro-deposited graphene electrode is adjusted by controlling the deposition time in order to get a value equal to the charge storage capacity of the Fc-MS-40 electrode (see the corresponding CV curves in different potential window with $1 \mathrm{M} \mathrm{LiCl}$ electrolyte in Supporting Information, Fig. S11). The energy storage characteristics of the as-prepared Fc-MS-40//Graphene hybrid-capacitor device are illustrated in Figure 6. As shown, it is able to work over the potential window from $0 \mathrm{~V}$ to $1.2 \mathrm{~V}$ at various scan rates ranging from $20 \mathrm{mV} / \mathrm{s}$ to $1000 \mathrm{mV} / \mathrm{s}$ (Fig. 6a). Despite the hybrid nature of the asymmetrical device, a pair of broad voltammetric signals corresponding to the redox processes related to ferrocene can still be observed in this potential window. The CV curves are well defined and symmetrical even at the scan rate of $1000 \mathrm{mV} \mathrm{s}^{-1}$, indicating the good rate performance. According to the literature, it is better to use the unit of battery $(\mathrm{C})$ rather than that of capacitor $(\mathrm{F})$, especially because the present system is actually a battery-capacitor hybrid device. ${ }^{44}$ By integrating these $\mathrm{CV}$ curves, the specific capacities are calculated for all scan rates investigated here, based on the total areas of the two electrodes (Fig. 6b). This device can deliver $0.74 \mathrm{mC} \mathrm{cm}^{-2}$ at the scan rate of 20 $\mathrm{mV} \mathrm{s}^{-1}$, and it can still maintain $57 \%$ at a scan rate of $500 \mathrm{mV} / \mathrm{s}(2.4 \mathrm{~s}$ for the charging/discharging 
time) and even $45 \%$ at a scan rate of $1000 \mathrm{mV} \mathrm{s}^{-1}$ (only $1.2 \mathrm{~s}$ for the charging/discharging time). This outstanding performance demonstrates that the redox reaction rate of the assembled redox molecules system through the electron-hopping process is fast and comparable to its double-layer type graphene counter electrode. The charge-discharge curves (Fig. 6c) exhibit, in contrast to battery, a distorted triangle charge-discharge shape without obvious plateau, also revealing the pseudo-supercapacitor nature of the Fc-MS-40//Graphene device, while the symmetrical curves indicate a good coulombic efficiency. The cycling stability of the device, as also determined by the $\mathrm{CV}$ method (see the corresponding results in Fig. S12) is quite robust as $74 \%$ capacity retention is maintained after 500 successive cycles. Ragone plots (Fig. 6d) further reveal that a high energy density of $0.13 \mu \mathrm{Wh} \mathrm{cm}^{-2}$ can be achieved at a power density of $12.8 \mu \mathrm{W} \mathrm{cm} \mathrm{cm}^{-2}$, a value still remaining as high as $0.07 \mu \mathrm{Wh} \mathrm{cm}^{-2}$ at higher power density $\left(180 \mu \mathrm{W} \mathrm{cm}{ }^{-2}\right)$.

(a)

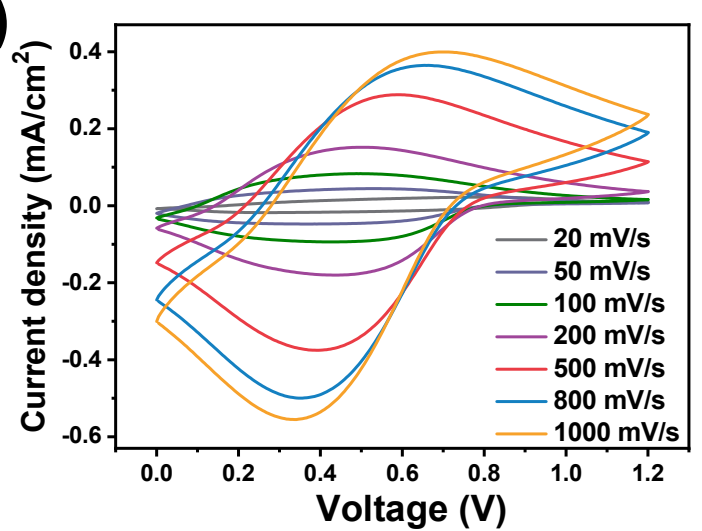

(c)

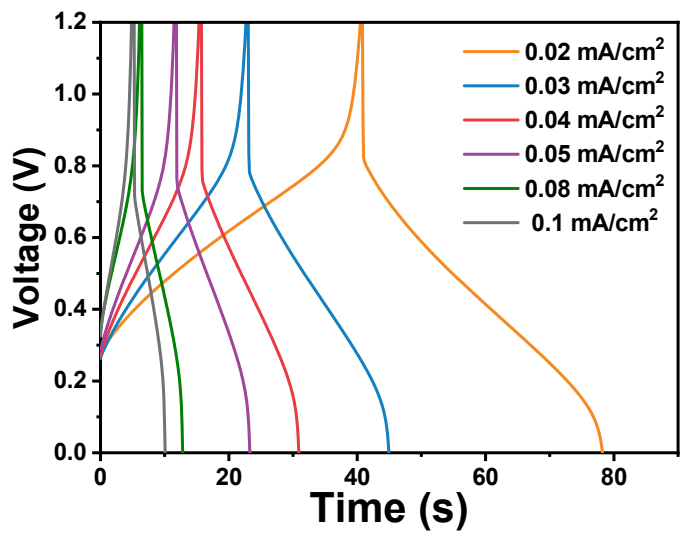

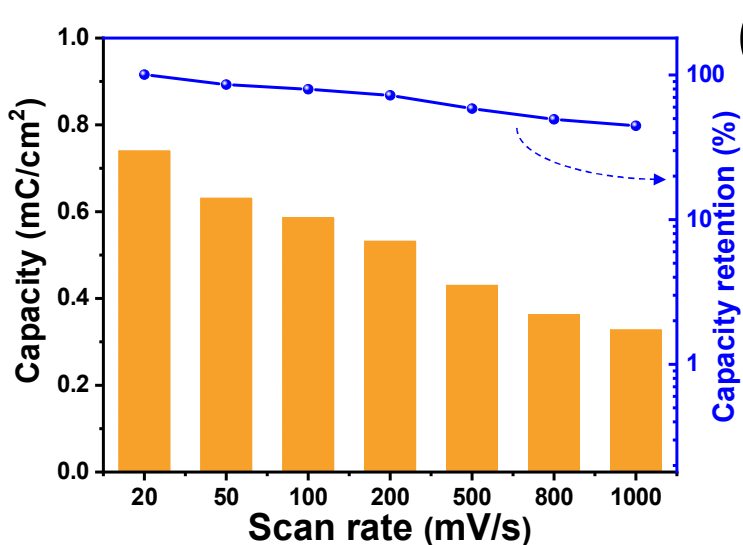

(b)

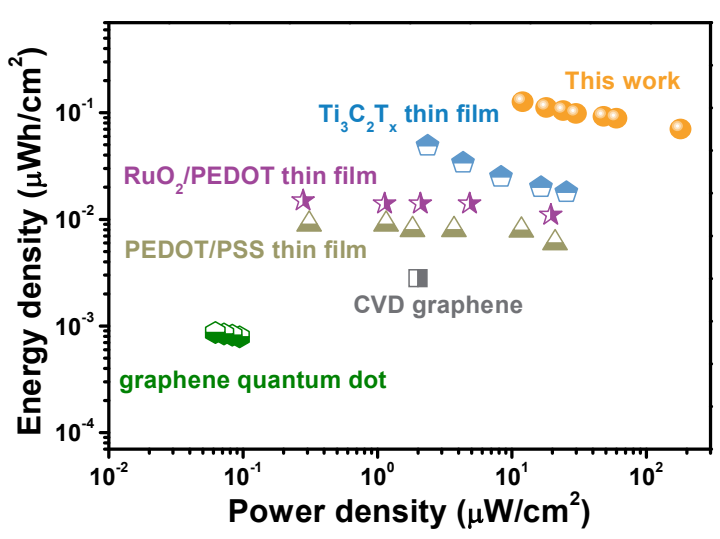

(d) 
Figure 6. Energy storage performance of the asymmetrical solid-state device (Fc-MS-40 as the anode, graphene as the cathode and the $\mathrm{PVA} / \mathrm{LiCl}$ as the electrolyte). (a) $\mathrm{CV}$ curves at various scan rates from 20 to $1000 \mathrm{mV} \mathrm{s}^{-1}$. (b) Corresponding specific capacity. (c) Charge/discharge curves at various current densities from $0.02 \mathrm{~mA} \mathrm{~cm}^{-2}$ to $0.1 \mathrm{~mA} \mathrm{~cm}{ }^{-2}$. (d) Ragone plots of the Fc-MS40//Graphene hybrid-device and PEDOT/PSS, ${ }^{37} \mathrm{RuO}_{2} / \mathrm{PEDOT},{ }^{38} \mathrm{Ti}_{3} \mathrm{C}_{2} \mathrm{~T}_{\mathrm{x}},{ }^{41}$ Graphene quantum dot, ${ }^{45}$ CVD graphene. ${ }^{46}$

\section{CONCLUSIONS}

Transparent and vertically-aligned mesoporous silica thin films anchoring redox-active species on their internal surface have been generated onto ITO electrodes and investigated as a novel family of energy storage materials. Charge propagation through such insulating coatings occurred via an electron-hopping process between the adjacent redox centers spatially isolated from each other by covalent bonding to the mesopore walls. Two processes governed their behavior as energy storage material, the charge transfer itself via electron hopping and the diffusion of counter ions to maintain the electroneutrality, both of them possibly restricting the rate of redox reactions. From experiments made on boundary cases (in terms of density of redox centers and degree of mesostructural order), it appears that the best performance of such electron-hopping based energy storage materials can be achieved by increasing the density of active sites (to improve the charge transfer rate) and the construction of widely-open and regular channels (in order to reduce the resistance to mass transport necessary to maintain charge balance). On that basis, the Fc-MS-40 thin film fulfilling well these two requirements can deliver a capacity of $105 \mathrm{C} \mathrm{cm}^{-3}(1.1 \mathrm{mC} \mathrm{cm}-$ ${ }^{2}$ ) at a current density of $0.4 \mathrm{~A} \mathrm{~cm}^{-3}$, and retain $48 \%$ of its capacity at a short charging time of 2.8 
s. A solid-state battery-capacitor hybrid device was also prepared by using graphene as counterelectrode, and it can deliver an energy density of $0.07 \mu \mathrm{Wh} \mathrm{cm}^{-2}$ at the high power density of 180 $\mu \mathrm{W} \mathrm{cm} \mathrm{cm}^{-2}$. Moreover, such transparent nanoporous silica membranes can be manufactured with other ethynyl-containing redox molecules (e.g., ethynylcobaltocenium), which broadens their possible application scenarios in the field of electrochemical energy storage.

\section{ASSOCIATED CONTENT}

\section{Supporting Information.}

The following file as available free of charge.

Additional experimental data (characterization and electrochemical measurements), especially for Fc-MS-20 and Fc-MS-60 samples, as well as the asymmetric solid-state device (PDF)

\section{AUTHOR INFORMATION}

\section{Corresponding Author}

*E-mail: alain.walcarius@univ-lorraine.fr (A.W.)

\section{ORCID}

Alain Walcarius: 0000-0003-3633-200X

\section{Notes}

The authors declare no competing financial interest. 


\section{ACKNOWLEDGMENT}

JW acknowledges a financial support from the China Scholarship Council for his doctoral studies. 


\section{REFERENCES}

(1) Wu, Z.; Chen, Z.; Du, X.; Logan, J. M.; Sippel, J.; Nikolou, M.; Kamaras, K.; Reynolds, J. R.; Tanner, D. B.; Hebard, A. F.; Rinzler, A. G.. Transparent, Conductive Carbon Nanotube Films. Science 2004, 305, 1273-1276.

(2) Ju, S.; Li, J.; Liu, J.; Chen, P. C.; Ha, Y. G.; Ishikawa, F.; Chang, H.; Zhou, C.; Facchetti, A.; Janes, D. B.; Marks, T. J. Transparent Active Matrix Organic Light-Emitting Diode Displays Driven by Nanowire Transistor Circuitry. Nano Lett. 2008, 8 , 997-1004.

(3) Park, S. I.; Xiong, Y.; Kim, R. H.; Elvikis, P.; Meitl, M.; Kim, D. H.; Wu, J.; Yoon, J.; Yu, C. J.; Liu, Z.; Huang, Y.; Hwang, K. C.; Ferreira, P.; Li, X.; Choquette, K.; Rogers, J. A. Printed Assemblies of Inorganic Light-Emitting Diodes for Deformable and Semitransparent Displays. Science 2009, 325, 977-981.

(4) Wang, X.; Li, Z.; Xu, W.; Kulkarni, S. A.; Batabyal, S. K.; Zhang, S.; Cao, A.; Wong, L. H. $\mathrm{TiO}_{2}$ Nanotube Arrays Based Flexible Perovskite Solar Cells with Transparent Carbon Nanotube Electrode. Nano Energy 2015, 11, 728-735.

(5) Jeon, I.; Yoon, J.; Kim, U.; Lee, C.; Xiang, R.; Shawky, A.; Xi, J.; Byeon, J.; Lee, H. M.; Choi, M.; Maruyama, S.; Matsuo, Y. High-Performance Solution-Processed Double-Walled Carbon Nanotube Transparent Electrode for Perovskite Solar Cells. Adv. Energy Mater. 2019, 9, 1-10.

(6) Zhang, C.; Nicolosi, V. Graphene and MXene-Based Transparent Conductive Electrodes and Supercapacitors. Energy Storage Mater. 2018, 222, 11-20. 
(7) Ma, D. L.; Ma, Y.; Chen, Z. W.; Hu, A. M. A Silk Fabric Derived Carbon Fibre Net for Transparent Capacitive Touch Pads and All-Solid Supercapacitors. J. Mater. Chem. A 2017, $5,20608-20614$.

(8) Zhang, Q.; Xu, W.; Sun, J.; Pan, Z.; Zhao, J.; Wang, X.; Zhang, J.; Man, P.; Guo, J.; Zhou, Z.; He, B.; Zhang, Z. Li, Q.; Zhang, Y.; Xu, L.; Yao, Y. Constructing Ultrahigh-Capacity Zinc-Nickel-Cobalt Oxide $@ \mathrm{Ni}(\mathrm{OH})_{2}$ Core-Shell Nanowire Arrays for High-Performance Coaxial Fiber-Shaped Asymmetric Supercapacitors. Nano Lett. 2017, 17, 7552-7560.

(9) Yu, S.; Yang, W.; Li, L.; Zhang, W. Improved Chemical Stability of ITO Transparent Anodes with a $\mathrm{SnO}_{2}$ Buffer Layer for Organic Solar Cells. Sol. Energy Mater. Sol. Cells 2016, 144, 652-656.

(10) Sawangphruk, M.; Srimuk, P.; Chiochan, P.; Sangsri, T.; Siwayaprahm, P. Synthesis and Antifungal Activity of Reduced Graphene Oxide Nanosheets. Carbon 2012, 50, 5156-5161.

(11) Xu, P.; Kang, J.; Choi, J. B.; Suhr, J.; Yu, J.; Li, F.; Byun, J. H.; Kim, B. S.; Chou, T. W. Laminated Ultrathin Chemical Vapor Deposition Graphene Films Based Stretchable and Transparent High-Rate Supercapacitor. ACS Nano 2014, 8, 9437-9445.

(12) Patil, A. M.; Lokhande, A. C.; Shinde, P. A.; Lokhande, C. D. Flexible Asymmetric SolidState Supercapacitors by Highly Efficient 3D Nanostructured $\alpha-\mathrm{MnO}_{2}$ and h-CuS Electrodes. ACS Appl. Mater. Interfaces 2018, 10, 16636-16649.

(13) Liu, X. Y.; Gao, Y. Q.; Yang, G. W. A Flexible, Transparent and Super-Long-Life Supercapacitor Based on Ultrafine $\mathrm{Co}_{3} \mathrm{O}_{4}$ Nanocrystal Electrodes. Nanoscale 2016, 8, $4227-4235$. 
(14) Blauch, D. N.; Savéant, J. M. Effects of Long-Range Electron Transfer on Charge Transport in Static Assemblies of Redox Centers. J. Phys. Chem. 1993, 97, 6444-6448.

(15) Finklea, H. O.; Hanshew, D. D. Electron-Transfer Kinetics in Organized Thiol Monolayers with Attached Pentaammine(Pyridine)Ruthenium Redox Centers. J. Am. Chem. Soc. 1992, $114,3173-3181$.

(16) Sato, K.; Ichinoi, R.; Mizukami, R.; Serikawa, T.; Sasaki, Y.; Lutkenhaus, J.; Nishide, H.; Oyaizu, K. Diffusion-Cooperative Model for Charge Transport by Redox-Active Nonconjugated Polymers. J. Am. Chem. Soc. 2018, 140, 1049-1056.

(17) Scibioh, M. A.; B. Viswanathan. Materials for Supercapacitor Applications; Elsevier: Amsterdam, 2020.

(18) Walcarius, A.; Sibottier, E.; Etienne, M.; Ghanbaja, J. Electrochemically Assisted SelfAssembly of Mesoporous Silica Thin Films. Nat. Mater. 2007, 6, 602-608.

(19) Goux, A.; Etienne, M.; Aubert, E.; Lecomte, C.; Ghanbaja, J.; Walcarius, A. Oriented Mesoporous Silica Films Obtained by Electro-Assisted Self-Assembly (EASA). Chem. Mater. 2009, 21, 731-741.

(20) Vilà, N.; Ghanbaja, J.; Aubert, E.; Walcarius, A. Electrochemically Assisted Generation of Highly Ordered Azide-Functionalized Mesoporous Silica for Oriented Hybrid Films. Angew. Chemie - Int. Ed. 2014, 53, 2945-2950.

(21) Vilà, N.; Ghanbaja, J.; Walcarius, A. Clickable Bifunctional and Vertically Aligned Mesoporous Silica Films. Adv. Mater. Interfaces 2016, 3, 1-11. 
(22) Vilà, N.; Walcarius, A. Electrochemical Response of Vertically-Aligned, FerroceneFunctionalized Mesoporous Silica Films: Effect of the Supporting Electrolyte. Electrochim. Acta 2015, 179, 304-314.

(23) Wildschek, M.; Rieker, C.; Jaitner, P.; Schottenberger, H.; Eberhard Schwarzhans, K. Ethynylcobaltocenium Compounds as Precursors for Bridged, Heteronuclear Oligometallocenes. Preparation and Reactions of Ethynyl-, Trimethylsilylethynyl- and Ferrocenylethynylcobaltocenium Salts. J. Organomet. Chem. 1990, 396, 355-361.

(24) Hummers, W. S.; Offeman, R. E. Preparation of Graphitic Oxide. J. Am. Chem. Soc. 1958, $80,1339$.

(25) Xu, W.; Jiang, Z.; Yang, Q.; Huo, W.; Javed, M. S.; Li, Y.; Huang, L.; Gu, X.; Hu, C. Approaching the Lithium-Manganese Oxides' Energy Storage Limit with $\mathrm{Li}_{2} \mathrm{MnO}_{3}$ Nanorods for High-Performance Supercapacitor. Nano Energy 2018, 43, 168-176.

(26) Gamero-Quijano, A.; Karman, C.; Vilà, N.; Herzog, G.; Walcarius, A. Vertically Aligned and Ordered One-Dimensional Mesoscale Polyaniline. Langmuir 2017, 33, 4224-4234.

(27) Guillemin, Y.; Etienne, M.; Aubert E.; Walcarius, A. Electrogeneration of Highly Methylated Mesoporous Silica Thin Films with Vertically-Aligned Mesochannels and Electrochemical Monitoring of Mass Transport Issues, J. Mater. Chem. 2010, 20, 67996807.

(28) Kovačević, I.; Pivac, B.; Dubček, P.; Radić, N.; Bernstorff, S.; Slaoui, A. A GISAXS Study of $\mathrm{SiO} / \mathrm{SiO}_{2}$ Superlattice. Thin Solid Films 2006, 511, 463-467. 
(29) Lim, M. H.; Stein, A. Comparative Studies of Grafting and Direct Syntheses of InorganicOrganic Hybrid Mesoporous Materials. Chem. Mater. 1999, 11, 3285-3295.

(30) Borello, E.; Zecchina, A.; Guglielminotti, E. The Infrared Spectra of 1,2,3-Triazole NOxides. J. Chem. Soc. B Phys. Org. 1966, 3, 1243-1245.

(31) Compton, R. G.; Banks, C. E. Understanding Voltammetry; Imperial College Press: London, 2013.

(32) Jiang, Y.; Liu, J. Definitions of Pseudocapacitive Materials: A Brief Review. Energy Environ. Mater. 2019, 2, 30-37.

(33) Niu, Z.; Zhou, W.; Chen, J.; Feng, G.; Li, H.; Hu, Y.; Ma, W.; Dong, H.; Li, J.; Xie, S. A Repeated Halving Approach to Fabricate Ultrathin Single-Walled Carbon Nanotube Films for Transparent Supercapacitors. Small 2013, 9, 518-524.

(34) Byon, H. R.; Lee, S. W.; Chen, S.; Hammond, P. T.; Shao-Horn, Y. Thin Films of Carbon Nanotubes and Chemically Reduced Graphenes for Electrochemical Micro-Capacitors. Carbon 2011, 49, 457-467.

(35) Chen, T.; Xue, Y.; Roy, A. K.; Dai, L. Transparent and Stretchable High-Performance Supercapacitors Based on Wrinkled Graphene Electrodes. ACS Nano 2014, 8, 1039-1046.

(36) Song, L.; Cao, X.; Li, L.; Wang, Q.; Ye, H.; Gu, L.; Mao, C.; Song, J.; Zhang, S.; Niu, H. General Method for Large-Area Films of Carbon Nanomaterials and Application of a SelfAssembled Carbon Nanotube Film as a High-Performance Electrode Material for an AllSolid-State Supercapacitor. Adv. Funct. Mater. 2017, 27, 474-487. 
(37) Higgins, T. M.; Coleman, J. N. Avoiding Resistance Limitations in High-Performance Transparent Supercapacitor Electrodes Based on Large-Area, High-Conductivity PEDOT:PSS Films. ACS Appl. Mater. Interfaces 2015, 7, 16495-16506.

(38) Zhang, C.; Higgins, T. M.; Park, S. H.; O’Brien, S. E.; Long, D.; Coleman, J. N.; Nicolosi, V. Highly Flexible and Transparent Solid-State Supercapacitors Based on $\mathrm{RuO}_{2} / \mathrm{PEDOT}$ PSS Conductive Ultrathin Films. Nano Energy 2016, 28, 495-505.

(39) King, P. J.; Higgins, T. M.; De, S.; Nicoloso, N.; Coleman, J. N. Percolation Effects in Supercapacitors with Thin, Transparent Carbon Nanotube Electrodes. ACS Nano 2012, 6, $1732-1741$.

(40) Jung, H. Y.; Karimi, M. B.; Hahm, M. G.; Ajayan, P. M.; Jung, Y. J. Transparent, Flexible Supercapacitors from Nano-Engineered Carbon Films. Sci. Rep. 2012, 2, 1-5.

(41) Zhang, C. J.; Anasori, B.; Seral-Ascaso, A.; Park, S. H.; McEvoy, N.; Shmeliov, A.; Duesberg, G. S.; Coleman, J. N.; Gogotsi, Y.; Nicolosi, V. Transparent, Flexible, and Conductive 2D Titanium Carbide (MXene) Films with High Volumetric Capacitance. $A d v$. Mater. 2017, 29, 1-9.

(42) Anderson Jr., J. H.; Parks, G. A. Electrical Conductivity of Silica Gel in the Presence of Adsorbed Water. J. Phys. Chem. 1968, 72, 3662-3668.

(43) Tian, W.; Hu, H.; Wang, Y.; Li, P.; Liu, J.; Liu, J.; Wang, X.; Xu, X.; Li, Z.; Zhao, Q.; Ning, H.; Wu, W.; Wu, M. Metal-Organic Frameworks Mediated Synthesis of One-Dimensional Molybdenum-Based/Carbon Composites for Enhanced Lithium Storage. ACS Nano 2018, $12,1990-2000$. 
(44) Zuo, W.; Li, R.; Zhou, C.; Li, Y.; Xia, J.; Liu, J. Battery-Supercapacitor Hybrid Devices: Recent Progress and Future Prospects. Adv. Sci. 2017, 4, 1600539.

(45) Lee, K.; Lee, H.; Shin, Y.; Yoon, Y.; Kim, D.; Lee, H. Highly Transparent and Flexible Supercapacitors Using Graphene-Graphene Quantum Dots Chelate. Nano Energy 2016, 26, 746-754.

(46) Yoo, J. J.; Balakrishnan K.; Huang, J.; Meunier, V.; Sumpter, B. G.; Srivastava, A.; Conway, M.; Reddy, A. L. M.; Yu, J.; Vajtai, R.; Ajayan, P. M. Ultrathin Planar Graphene Supercapacitors. Nano Lett. 2011, 11, 1423-1427. 